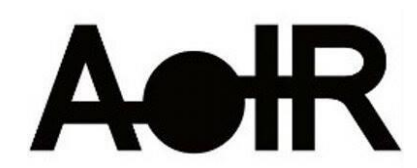

Selected Papers of \#AoIR2019:

The $20^{\text {th }}$ Annual Conference of the

Association of Internet Researchers

Brisbane, Australia / 2-5 October 2019

\title{
DISAPPOINTING AND BEING DISAPPOINTED: VIDEO GAME PLAYER TRUST IN EACH OTHER
}

Christine Tomlinson

University of California, Irvine

\section{Extended Abstract}

Video games often serve as a means of relaxation and enjoyment, but many factors become obstacles in the way of this goal. Specifically, there are a variety of reasons that players have grown to feel uncomfortable with one another. Online, video game consumers are frequently in positions where they need to rely on each other, but also need to assess the level of safety in these encounters. While previous work has focused a great deal on gendered hostilities, this project finds that the general population of players have concerns related to negative interactions. Furthermore, while seen as unacceptable, these encounters have become largely normalized.

When it comes to trust, the fact that many players begin their multiplayer habits through already established friend networks should create a more comfortable space (Taylor, $2006,2008)$. However, this does not exclude or reduce the possibility of expanding those networks. The majority of online players make new friends in online game settings and many are even comfortable sharing private information with these new online ties (Cole \& Griffiths, 2007; Bourgonjon, Vandermeersche, De Wever, Soetaert, \& Valcke, 2015). In addition to reinforcing old bonds and making new ones, the presence of teambased gameplay encourages more cooperative behaviors and experiences (Greitemeyer \& Cox, 2013).

Still, negative interactions happen frequently among players, including trolling or grief play and cheating - methods of harassing or dishonestly overcoming other players (Taylor, 2006; Nardi, 2010). These interactions commonly produce negative results due to players exploiting, harassing, or reinforcing a sense of hierarchy among each other (Ruben \& Camm, 2013). Women have also been noted as receiving interactions like these much more frequently than men (Kuzenkoff \& Rose, 2012).

Suggested Citation (APA): Tomlinson, C. (2019, October 2-5). Disappointing and being disappointed: Video game player trust in each other. Paper presented at AoIR 2019: The 20 $0^{\text {th }}$ Annual Conference of the Association of Internet Researchers. Brisbane, Australia: AolR. Retrieved from http://spir.aoir.org. 
To better understand these dynamics among video game players, I use qualitative methods to collect data through 54 interviews and approximately 1900 posts from five online gaming forums. Three of these forums are focused on women. In interviews, players are asked about their experiences with and perceptions of people in gaming culture. For online forum posts, live conversations and targeted searches for specific terms related to gender, hostility, and online play are used to analyze how players talk about multiplayer situations and toxicity in the gaming community. Both interviews and online forum data are coded for themes and patterns.

For many players, trust in gaming is not something that comes easily. The majority of players in interviews and online forums report feeling like they cannot necessarily play certain games or genres without encountering toxicity or harassment. The types of harassment discussed range from hearing people generally saying unpleasant things over the microphone to being told to commit suicide for not being up to par in terms of their skill.

These hostilities do take on gendered appearances as well. Women discuss circumstances where they are assumed not to be good enough at games and have been approached by male players who want to explain how everything works. Additionally, women note many instances of sexualized harassment. These behaviors include tendencies for male players to flirt with, make suggestive comments to, or solicit female players. It also includes male players telling female players to "get back in the kitchen" or service their male partners sexually. This can have devastating effects, with the stress and pressure of playing with a team - even those comprised of people the player knows - becoming so burdensome that emotional breakdowns can happen because harassment is anticipated and players feel they cannot live up to expectations.

Interestingly, while women discuss very targeted and specific kinds of harassment, they report receiving less of it than men. This is likely due to the fact that they are more prone to avoid multiplayer games to begin with because of concerns over the reportedly toxic experiences that women have. Men frequently get a later start with being driven to avoid particular games or game genres to try to evade harassment. This happens after initially encountering it, with League of Legends being the most frequently cited example. However, multiplayer games in general are shunned by many players regardless of gender because of these concerns. For instance, players note that they have been dissuaded from pursuing multiplayer play because of being judged for their skill in previous multiplayer attempts.

These behaviors have largely become expected. The majority of players in interviews and online forums discuss multiplayer experiences as predictably negative. If this is the case, why would players continue to play multiplayer games? Online forum discussions illuminate a possible contributing factor: players have just come to accept toxicity. In several forum posts, on both general and women-focused forums, players recall days of cooperation and support with other players. On the forums specifically, users discuss what can possibly be done, with most giving up hope that the community can change, citing toxicity as how things work now. Beyond this, players also lack trust in companies to do anything, regularly mentioning that reports seem to do nothing to alleviate the 
issues or reduce hostile interactions.

Overall, players have come to build a sense of general distrust in the gaming community. Players anticipate harassment and mistreatment, with an understanding that this is how the culture is currently constructed. Feeling defeated, attempts to brainstorm solutions are typically shut down and most players appear to either accept it and stay quiet or give up on particular genres or games all together. This should be of concern for the video game industry, as this greatly affects their sales, but also to us as the public. With the growth of video games as a form of leisure for many, and the potential negative effects of hostility and toxicity from other players, this is putting many who want to explore video games as a hobby at risk of stress outcomes and a general breakdown in trust when it comes to many aspects of gaming.

\section{References}

Bourgonjon, J., Vandermeersche, G., De Wever, B., Soetaert, R., \& Valcke, M. (2016). Players' perspectives on the positive impact of video games: A qualitative content analysis of online forum discussions. New Media \& Society, 18(8), 1732-1749.

Cole, H., \& Griffiths, M. D. (2007). Social interactions in massively multiplayer online role-playing gamers. Cyberpsychology \& Behavior, 10(4), 575-583.

Greitemeyer, T., \& Cox, C. (2013). There's no "l" in team: Effects of cooperative video games on cooperative behavior. European Journal of Social Psychology, 43(3), 224228.

Kuzenkoff, J. H., \& Rose, L. M. (2012). Communication in multiplayer gaming:

Examining player responses to gender cues. New Media \& Society 15(4):541-556.

Nardi, B. A. (2010). My life as a night elf priest: An anthropological account of World of Warcraft. Ann Arbor: University of Michigan Press.

Rubin, V. L., \& Camm, S. C. (2013). Deception in video games: Examining varieties of griefing. Online Information Review, 37(3), 369-387.

Taylor, T. L. (2006). Play between worlds: Exploring online game culture. Cambridge: The MIT Press.

Taylor, T. L. (2008). Becoming a player: Networks, structure, and imagined futures. In Y. B. Kafai, C. Heeter, J. Denner, \& J. Y. Sun (Eds), Beyond Barbie \& Mortal Kombat: New perspectives on gender and gaming (pp. 50-64). MA: MIT Press. 